\title{
Paraphysomonas imperforata (Protista, Chrysomonadida) under different turbulence levels: feeding, physiology and energetics
}

\author{
Francesc Peters ${ }^{1, *}$, Joon W. Choi ${ }^{1, * *}$, Tom Gross ${ }^{2}$ \\ ${ }^{1}$ Institute of Ecology, University of Georgia, Athens, Georgia 30602-2202, USA \\ ${ }^{2}$ Skidaway Institute of Oceanography, 10 Ocean Science Circle, Savannah, Georgia 31411, USA
}

\begin{abstract}
Ingestion rates of Paraphysomonas imperforata Lucas feeding on bacteria were studied under a range of turbulence intensities. Turbulence had no effect on per cell ingestion rates of flagellates either upon initial exposure to turbulent conditions or after $12 \mathrm{~h}$ under the turbulence treatment. Flagellates increased in numbers and decreased in size at all turbulence intensities as well as in nonturbulence treatments, probably as an adaptation to an environment with lower food concentration than the stock cultures. Flagellates under high turbulence (ca $15 \mathrm{~cm}^{2} \mathrm{~s}^{-3}$ ) were significantly smaller and more abundant after $12 \mathrm{~h}$ than in the non-turbulence treatment. Total grazing on the bacterial population is thus implied to be higher under high turbulence. Flagellate gross growth efficiencies were not statsstically different between the turbulence treatments and their non-turbulent controls. When the responses to turbulence are compared to those for calanoid copepods some similarities can be seen (decrease in size and faster development times)
\end{abstract}

KEY WORDS: Small-scale turbulence Paraphysomonas imperforata - lngestion rates - High turbulence Size decrease Growth efficiency

\section{INTRODUCTION}

Small-scale turbulence has been shown to affect the physiology and feeding rates of small planktonic organismas. Prominent in this field are the studies with calanoid copepods and fish larvae (Rothschild \& Osborn 1988, Costello et al. 1990, Haury et al. 1990, Marrasé et al. 1990, Sundby \& Fossum 1990, MacKenzie \& Leggett 1991, Yamazaki et al. 1991, Saiz \& Alcaraz 1992a, Saiz et al. 1992). Although much of this information is theoretical or based on correlation, we can start to draw some general conclusions. Contact rates between these organisms and their prey particles are increased under turbulence. Turbulence increases the velocity of particles with a random direction and a

\footnotetext{
- Present address: Institut de Ciències del Mar, Passeig Joan de Borbó s/n, E-08039, Barcelona, Catalunya, Spain

E-mail: cesc@icm.csic.es

-Present address: 1315 Buena Court, Richland, Washington 99352, USA
}

mean speed that depends on turbulence intensity. Since uncorrelated particle velocity directly affects encounter rates, these are also increased (Rothschild \& Osborn 1988). Theoretically, this effect can be seen down to the size scale of the smallest eddies, which is determined by the intensity of the turbulent kinetic energy dissipation rate $(\varepsilon)$ and the kinematic viscosity (Tennekes \& Lumley 1972). The Kolmogorov cut-off size scale in the ocean is calculated to be between 1 and $10 \mathrm{~mm}$ based on current estimates of $\varepsilon$ for the pelagic mixed layer. Below the Kolmogorov scale motions are dominated by viscous laminar flow, while above the Kolmogorov scale advective motions of turbulent eddies dominate.

Feeding rates under turbulence are not always increased with higher encounter rates. There could be interferences with the feeding currents created by the predator or more complex behavioral responses (Marrasé et al. 1990). Additionally, there seem to be changes in the physiology of the predators experiencing a turbulence regime. Saiz \& Alcaraz (1992a) reported 
that copepods had increased ammonium and phosphorus excretion and in general an increase in metabolic rates and decreased development time (Saiz \& Alcaraz 1991) resulting in lower gross growth efficiencies (Saiz et al. 1992).

Research on the effects of turbulence on smaller organisms such as protista has been driven by the studies on dinoflagellates (White 1976, Pollingher \& Zemel 1981, Thomas \& Gibson 1990, Berdalet 1992, Thomas \& Gibson 1992). Dinoflagellates are important for fisheries because some produce toxic 'blooms' known as red tides. These outbreaks appear to require a previous period of calm water, and winds seem to inhibit them (Thomas \& Gibson 1990). Turbulence has been shown to decrease the cellular division of dinoflagellates (Pollingher \& Zemel 1981), and the cause has been narrowed down to an inhibition of the nuclear division in Gymnodinium nelsonii (Berdalet 1992) resulting in an increase in cell volume. In ciliates, Hellung-Larsen \& Lyhne (1992) reported lower growth rates in Tetrahymena pyriformis under turbulence, but higher order interactions depending on ciliate concentration seemed to be present.

More recently, the effects of turbulence on those protists that have a prominent role in the transfer of energy and materials at the base of aquatic food webs have begun to be addressed. Shimeta (1993) predicted that even below the Kolmogorov size scale, turbulence could increase the encounter rates of small-size predators with prey particles, owing to advection processes produced by the remaining laminar shear field. Shimeta et al. (1995) tested their ideas experimentally and found mixed results. In most cases, including 3 chrysomonad flagellates, there was no effect of turbulence on ingestion rates. Departures from their hypothesis were attributed to species-specific morphologies and feeding mechanisms

Peters \& Gross (1994) performed long-term feeding experiments. Grazing rates on bacteria, as measured by the decrease over time of a prey surrogate, were significantly higher under turbulence. This difference was observed both in the field, with the natural microplankton community $(<200 \mu \mathrm{m})$, and in the laboratory, with Paraphysomonas imperforata. Over a $24 \mathrm{~h}$ experiment, bacteria were grazed faster despite no difference in initial ingestion rates (measured by prey surrogate uptake into food vacuoles). Protozoa also showed differences in size change in both treatments. Some physiological and/or behavioral change under turbulence was suspected.

In this study we explore the possibility of a lag in the effect of turbulence on ingestion rates, so that they would not show differences at the beginning of the incubation, but would be affected by turbulence sometime later. We base this reasoning on indirect evidence (Peters \& Gross 1994, Peters \& Choi unpubl.) that points more toward an effect of turbulence on the physiology and perhaps swimming and feeding behavior of the organisms than to a direct effect on encounter rates. Since ingestion rate depends strongly on food particle concentration, we performed feeding experiments under conditions such that food concentration did not change much over the incubation period. We also extended these measurements to a range of turbulence intensities that included high energy dissipation levels, expected near the surface during storm events, as well as lower levels which are more in accordance with average upper mixed layer conditions

\section{METHODS}

Turbulence generation and quantification. We generated turbulence in the experimental vessels by means of vertically oscillating grids. The system set up has been described previously (Peters \& Gross 1994). The oscillation of the grid was not restricted to the bottom of the beaker but ranged over almost the entire water depth. This prevented a vertical gradient of turbulence conditions that could have affected the distribution of flagellates and/or their prey particles. A variable speed DC gear motor (torque $12 \mathrm{lb}$-in = $1.4 \mathrm{~N} \mathrm{~m}$ ) and 2 fixed speed AC gear motors $(7 \mathrm{rpm}$, torque $9.4 \mathrm{lb}$-in $\approx 1.1 \mathrm{~N} \mathrm{~m} ; 1.2 \mathrm{rpm}$, torque $6 \mathrm{lb}$-in $\approx$ $0.68 \mathrm{~N} \mathrm{~m}$ ) gave a range of 7 oscillation rates. The exact rpm was obtained by calculating the mean of 10 timings of a number of grid oscillations (depending on rpm)

In order to estimate turbulence, we measured the vertical component $(v)$ and one of the horizontal components $(u)$ of water velocity locally at different points in the beaker. Rutile (titanium dioxide) particles $(2-3 \mu \mathrm{m})$ were used as tracers of water movement, and particle velocities were measured with a 2-axis laser Doppler anemometer. For optical reasons these measurements were made in an acrylic plastic replicate of the experimental glass beakers. Each component of velocity was sampled at a rate of $100 \mathrm{~Hz}$ for $2 \mathrm{~min}$. At $1.2 \mathrm{rpm}$ data were sampled for $8 \mathrm{~min}$ at $25 \mathrm{~Hz}$.

The passage of the grid through a point in the beaker gave clear signatures to the velocity time series (Fig. 1). Turbulent kinetic energy $(q)$ was estimated as a function of time within a grid oscillation. We used the ensemble standard deviation of the velocity components once the velocity series were split and aligned mathematically with the peak signatures (Peters \& Gross 1994). A time averaged $q$ was calculated by integration over an oscillation period: 


$$
\text { ave } q=\frac{1}{T} \int_{0}^{T} q_{1} \mathrm{~d} t
$$

where $T$ is the time of an oscillation period, $q_{t}$ is the value of turbulent kinetic energy at time $t$ and $\mathrm{d} t$ is the data sampling interval.

We used the decay of $q$ over time after the passage of the grid (Fig. 2) to estimate energy dissipation rate $(\varepsilon)$. This rate was high after the passage of the grid and kept decreasing until the next passage. A time averaged $\varepsilon$ was calculated in the same fashion as ave $q$, except that $T$ was not the whole oscillation period but that portion of it that showed a decreasing $q$ trend.

A theoretically derived $\varepsilon$ was calculated by assuming a constant drag coefficient of 0.7 for the grid and thereby estimating the energy input per cycle to the water in the beaker (Peters \& Gross 1994). The drag coefficient was estimated from falling grid measurements. These theoretical estimates serve for comparison purposes.

Feeding experiments. The ingestion rate of Paraphysomonas imperforata Lucas feeding on the bacterium $\mathrm{T} 1-\mathrm{a}$ marine Vibrio-like isolate (Choi \& Peters 1992) - was assessed using fluorescently labeled bacteria (FLB). Experiments were conducted at different turbulence intensities. For each turbulence intensity, the setup consisted of 6 experimental units ( $1 \mathrm{l}$ glass beakers). Three of the units had oscillating grids creating turbulence and the other 3 were non-turbulence controls. Ingestion rates were measured at 2 different times for each turbulence intensity once at time 0 and once after $12 \mathrm{~h}$.

FLB were prepared from T1 following the procedure developed by Sherr et al. (1987) with minor modifications as in Peters \& Gross (1994). Aliquots of $1 \mathrm{ml}$ were frozen $\left(-20^{\circ} \mathrm{C}\right)$ until use. Before each experiment FLB were thawed, resuspended in $10 \mathrm{ml}$ of $0.2 \mu \mathrm{m}$ filtered sterile sea water, sonicated to disrupt cell clumping, and enumerated. For each turbulence intensity, a protozoan batch ( $150 \mathrm{ml}$ in a $250 \mathrm{ml}$ Erlenmeyer flask) was grown on T1 to late exponential phase. A separate culture of $\mathrm{T} 1(500 \mathrm{ml}$ in a $1 \mathrm{l}$ Erlenmeyer flask) was also grown at the same time. T1 had a size of ca $1 \times 2 \mu \mathrm{m}$, corresponding to a cell volume of $1.57 \mu \mathrm{m}^{3}$. The cultures were grown at $10^{\circ} \mathrm{C}$ with slight stirring to ensure aerobic conditions.
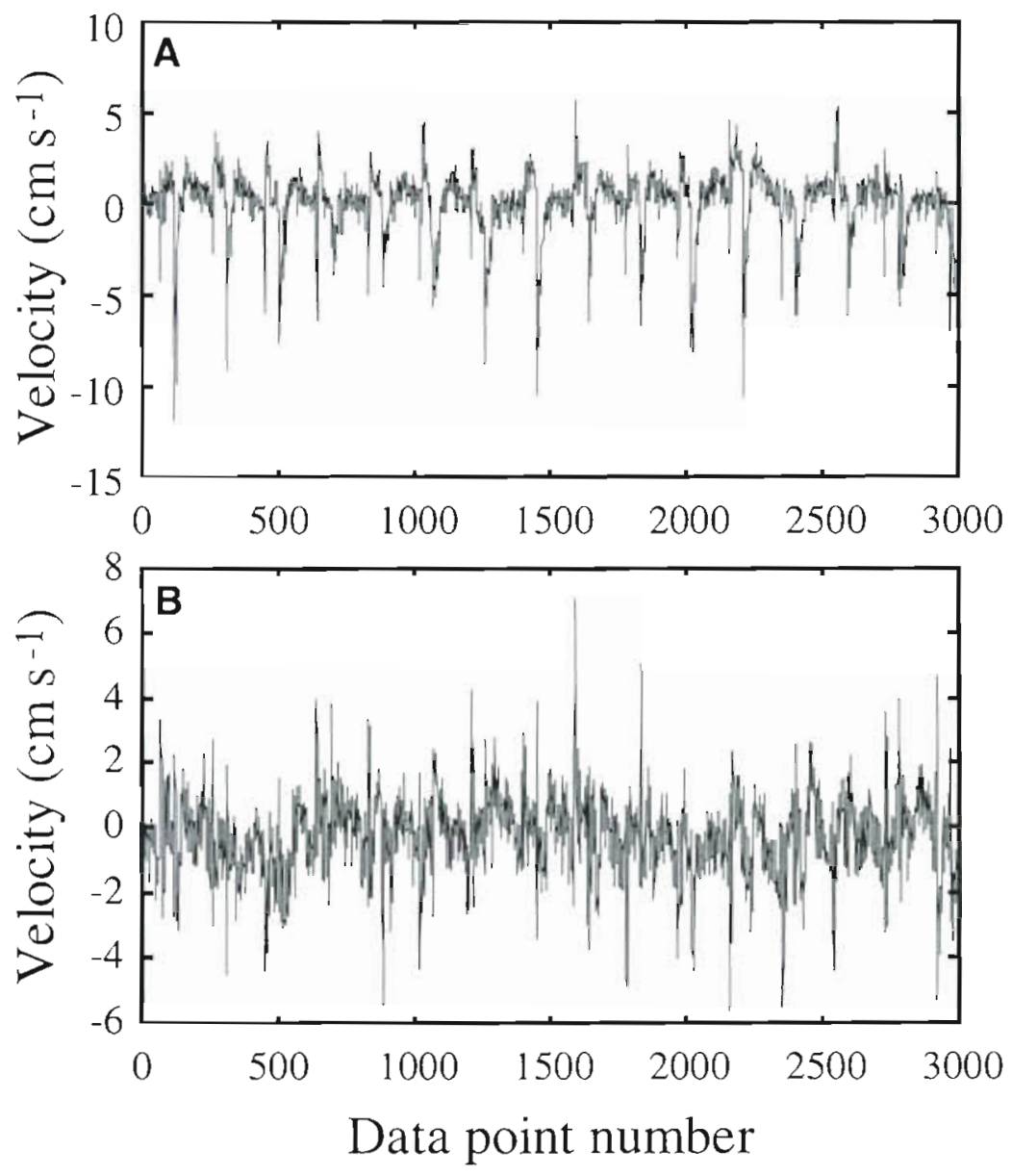

Fig. 1. Example of (A) vertical and (B) horizontal velocity time series for the first 3000 points (full series is 11776 points per component) sampled with the laser Doppler anemometer. Grid oscillation rate was $31.5 \mathrm{rpm}$. Sampling frequency was $100 \mathrm{~Hz}$. Data sampled at $7 \mathrm{~cm}$ from the bottom of the beaker and $2 \mathrm{~cm}$ off center

Simple calculations (not shown) using previously assessed growth and ingestion rates (Choi \& Peters 1992. Choi 1994, Peters \& Gross 1994) served to carefully choose the initial bacterial and flagellate concen-

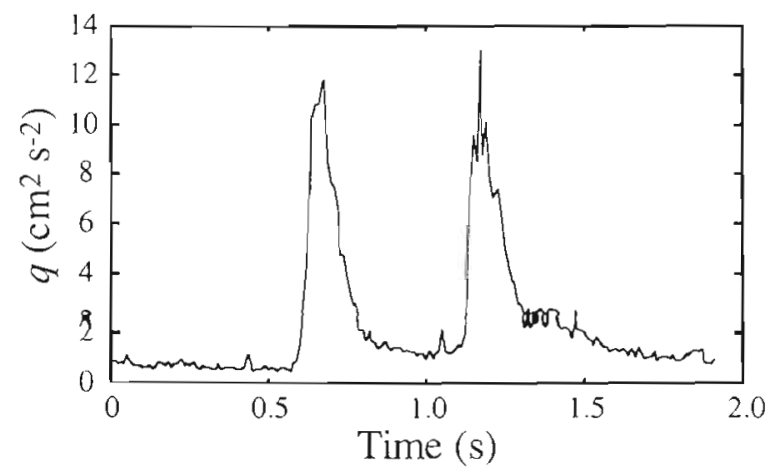

Fig. 2. Time course of turbulent kinetic energy for 1 grid oscillation period. Obtained from the data of Fig. 1 
trations for a minimal impact on the bacterial population after a $12 \mathrm{~h}$ incubation. At the time of the experiment, flagellates in culture were counted with a hemocytometer. A subsample was then resuspended in $4.8 \mathrm{l}$ of $0.2 \mu \mathrm{m}$ filtered sterile sea water to achieve a concentration of $10^{3}$ flagellates $\mathrm{ml}^{-1}$. The appropriate amount of bacterial culture was added to reach a bacterial concentration of $10^{7}$ bacteria $\mathrm{ml}^{-1}$, a food concentration that was non-saturating for Paraphysomonas imperforata (Fig. 3). This water was mixed to assure homogeneity and $800 \mathrm{ml}$ were added to each of the 6 experimental vessels. The entire procedure and the experiments were done in a walk-in cold room at $10^{\circ} \mathrm{C}$ to minimize stress on the flagellates owing to temperature fluctuations

The experimental organisms were left to acclimate for $20 \mathrm{~min}$. Then FLB were added to each vessel for a concentration of $3 \times 10^{6} \mathrm{FLB} \mathrm{m} \mathrm{m}^{-1}$ (30\% of live bacteria). Samples $(20 \mathrm{ml})$ were taken immediately and every 2 to $3 \mathrm{~min}$ for $20 \mathrm{~min}$, and fixed with ice-cold glutaraldehyde for a final concentration of fixative of $1 \%$.

The entire experiment was then immediately repeated using the same protozoan and bacterial batches. However, in this case, FLB uptake was measured $12 \mathrm{~h}$ after the start of the experiment.

Sample processing and calculations. Two subsamples were stained with 4,6-diamidino-2-phenylindole (DAPI), and filtered onto black polycarbonate filters. One

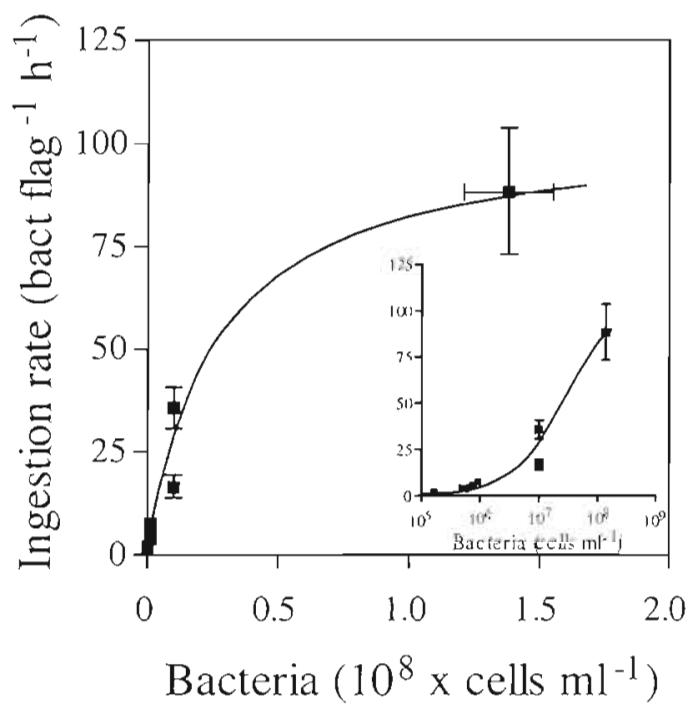

Fig. 3. Functional response curve of Paraphysomonas imperforata feeding on T1 under still water. Temperature of incubation was $10^{\circ} \mathrm{C}$. Ingestion rates were estimated using the direct FLB technique described in. 'Methods' section. Points are averages of 3 replicates and error bars are 1 SE. The line shows the non-linear regression (following a Michaelis-Menten equation) from the non-averaged data $\left(K_{M}=2.71 \times 10^{\%}\right.$ bact $\mathrm{ml}^{-1}$, Max. Ingestion rate $=103 \mathrm{bact} \mathrm{flag}^{-1} \mathrm{~h}^{-1}$. Corrected $\mathrm{r}^{2}=$ 0.855 ). Inset shows the same data plotted with a logarithmic $x$-axis to better show the distribution of points subsample was for bacteria and FLB enumeration (1 $\mathrm{ml}$ onto a $0.2 \mu \mathrm{m}$ filter), and the other one for flagellate sizing and enumeration of FLB inside flagellate food vacuoles ( 15 to $18 \mathrm{ml}$ onto a $2 \mu \mathrm{m}$ filter). The filters were mounted on microscope slides and viewed at $1250 \times$ with an Olympus BH-2 epifluorescence microscope.

For each sample, between 100 and 400 flagellates were scanned for FLB inside their vacuoles (at least 200 FLB were counted), and the diameters of about 50 flagellates were measured. Protozoan cell volumes were calculated from average cell diameters assuming a spherical shape for the flagellates. A third subsample $(0.1 \mathrm{ml})$ was placed in a Palmer counting chamber and scanned at $250 \times$ to estimate flagellate concentration. Not all counts were done for all samples. Because of the short time intervals between the samples of the FLB uptake series, bacterial and flagellate concentration and flagellate sizing were done at time 0 and time $12 \mathrm{~h}$. Instantaneous ingestion rates were obtained from the linear portion of plots of FLB flagellate $e^{-1}$ versus time, and converted to total bacteria flagellate $\mathrm{e}^{-1} \mathrm{~h}^{-1}$ using the proportion of FLB with respect to total bacteria.

The 3 turbulence intensity experiments were done on separate days, and consequently each had its own non-turbulence treatment as control. For each experiment, dependent variables such as bacterial and flagellate concentrations, cell volume of flagellates and ingestion rate were analyzed using 2-way ANOVA tests. The factors were: 'turb' (with 2 treatments for the presence or absence of turbulence), and 'time' (with 2 treatments for time 0 and time $12 \mathrm{~h}$ ).

A percentage of change over the $12 \mathrm{~h}$ incubation was also calculated for the different dependent variables:

$$
\% \text { change }=\frac{X_{i} X_{i}}{X_{1}} \times 100
$$

where $X$ is any of the dependent variables and the subindices indicate initial (i) and $12 \mathrm{~h}$ (f) values. The percentages for turbulence treatments were compared to the percentages for the respective non-turbulence controls using 2-tail t-tests. This statistical analysis is complementary to the ANOVA analysis giving a better picture of the differences between the turbulence and non-turbulence treatments and their variations over time, especially when interactions appear between factors.

\section{RESULTS}

\section{Turbulence levels}

Average turbulent kinetic energy increased with increasing oscillation rate. After accounting for oscillation rate, there was no pattern in the horizontal distrib- 
ution of $q$ ( $p=0.612$ ). Vertically, $q$ was significantly lower (within a factor of 10 ) only in the upper $1 \mathrm{~cm}$ of the beaker, through which the grid did not pass. In the remainder of the water column, $q$ was homogeneous $(\mathrm{p}=0.473)$ although the trend was towards slightly smaller values away from the center of the beaker

Measured average energy dissipation rates also increased with increasing grid oscillation rate (Fig. 4A, Table 1). As with average $q$, there was horizontal homogeneity in average $\varepsilon$. Vertically, there was more of a trend to somewhat smaller values away from the grid center. However, this trend was not statistically significant ( $p=0.191$ ) and values were within a factor of 2 .

At the 2 lowest rpm settings, despite the best possible velocity peak alignment, the time course of turbulent kinetic energy did not show a clear peak trend that would correspond to the passage of the grid. Consequently, $\varepsilon$ could not be measured directly. Theoretically, dissipation rate should scale with turbulent kinetic energy as:

$$
\varepsilon=c q^{3 / 2}
$$

where $c$ is a constant. We used the measurements of $\varepsilon$ and $q$ at the higher oscillation rates to estimate $c$ (Fig. 4B). From this relationship average $\varepsilon$ was estimated for settings of 7.01 and $1.23 \mathrm{rpm}$ (Table 1). Other statistical relationships between $q$ and $\varepsilon$ were explored (linear, polynomial, exponential, power, and logarithmic). Only a polynomial function of degree 2 was slightly better $\left(r^{2}=0.993\right)$, but had no theoretical basis.

Feeding experiments were performed at 1.23, 7.01 and $31.5 \mathrm{rpm}$. Hereafter, we refer to them as the low, medium and high level of turbulence, respectively. These labels distinguish the relative importance of turbulence in the experiments, but have no quantitative meaning outside the context of this paper. The high level was chosen for comparison with other studies that were also conducted at this level (Peters \& Gross 1994, Peters \& Choi unpubl.).

Table 1. Grid oscillation rates and their associated calculated and measured energy dissipation rates $\left(\varepsilon, \mathrm{cm}^{2} \mathrm{~s}^{-3}\right)$

\begin{tabular}{|ccccc|}
\hline $\begin{array}{l}\text { Oscillation } \\
\text { rate }(\mathrm{rpm})\end{array}$ & $\begin{array}{l}\text { Feeding } \\
\text { expt }\end{array}$ & $\begin{array}{c}\varepsilon \\
\text { (theoretical) }\end{array}$ & $\begin{array}{c}\varepsilon \\
\text { (measured) }\end{array}$ & $\begin{array}{c}\text { Discrepancy } \\
(\%)\end{array}$ \\
\hline $1.23^{\mathrm{a}}$ & Low & $7.3 \times 10^{-4}$ & $0.050^{\mathrm{b}}$ & 98.5 \\
$7.01^{\mathrm{a}}$ & Medium & 0.14 & $0.15^{\mathrm{b}}$ & 6.67 \\
12.4 & & 0.75 & 5.3 & 50.7 \\
21.8 & & 15 & 22.6 \\
$31.5^{\mathrm{a}}$ & High & 12 & 26 & 20.0 \\
42.6 & & 30 & 53 & 13.3 \\
53.0 & 59 & 10.2 \\
'Oscillation rates at which feeding experiments were conducted \\
'Calculated by regression from information at higher oscillation \\
rates
\end{tabular}
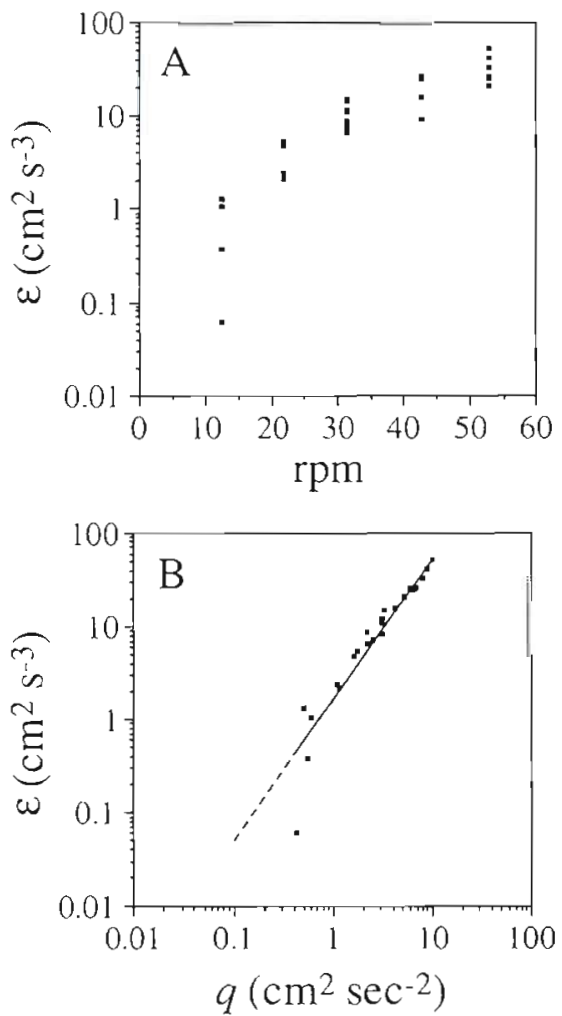

Fig. 4. Measured average energy dissipation rate versus (A) oscillation rate and (B) average turbulent kinetic energy. The equation for the regression in $(B)$ is: $\varepsilon=1.5768 q^{3 / 2} ; r^{2}=0.989$. Dashed portion corresponds to the extrapolation to lower values

\section{Biotic parameters}

Bacterial concentrations did not change significantly after $12 \mathrm{~h}$ (Fig, 5, Table 2). Only in the medium level turbulence experiment were concentrations after $12 \mathrm{~h}$ higher than initially, but there was no difference owing to turbulence. Surprisingly, the non-turbulence treatments showed somewhat more variation between experiments than the turbulence treatments did, although the changes were not statistically significant.

Flagellate concentration increased over time from 2- to 3.6-fold in the different experiments (Fig. 6). After $12 \mathrm{~h}$, flagellate concentration was statistically different between treatments only in the high turbulence level experiment (Table 2). Flagellate cell volumes followed a trend opposite from flagellate concentration, i.e they decreased with respect to time (Fig. 6). Again, the high turbulence level experiment was the only one which showed statistical differences in cell volume at the end of the experiment. In this case, flagellates under the turbulence treatment were smaller than under non-turbulence. 
The turbulence treatment did not significantly affect per cell ingestion rates at any turbulence level (Fig. 7). Final ingestion rates (after $12 \mathrm{~h}$ ) remained statistically indistinguishable from initial ingestion rates, with the exception of the medium turbulence level (Table 2). At this level, ingestion rates in both treatments increased from an average of 27.8 to 37.8 bacteria flagellate ${ }^{-1} h^{-1}$ after 12 h.

Since flagellate cell volume changes over time, ingestion rates normalized for predator cell volume were also calculated (Fig. 7). Table 2 shows that the statistical results are the same whether ingestion rates are normalized or not. Only in the case of the high turbulence experiment did the difference between the turbulent and non-turbulent treatments approach significance. The percentage change over time in ingestion rates normalized for predator cell volume presented a $\mathrm{p}$-value of 0.06 between treatments compared

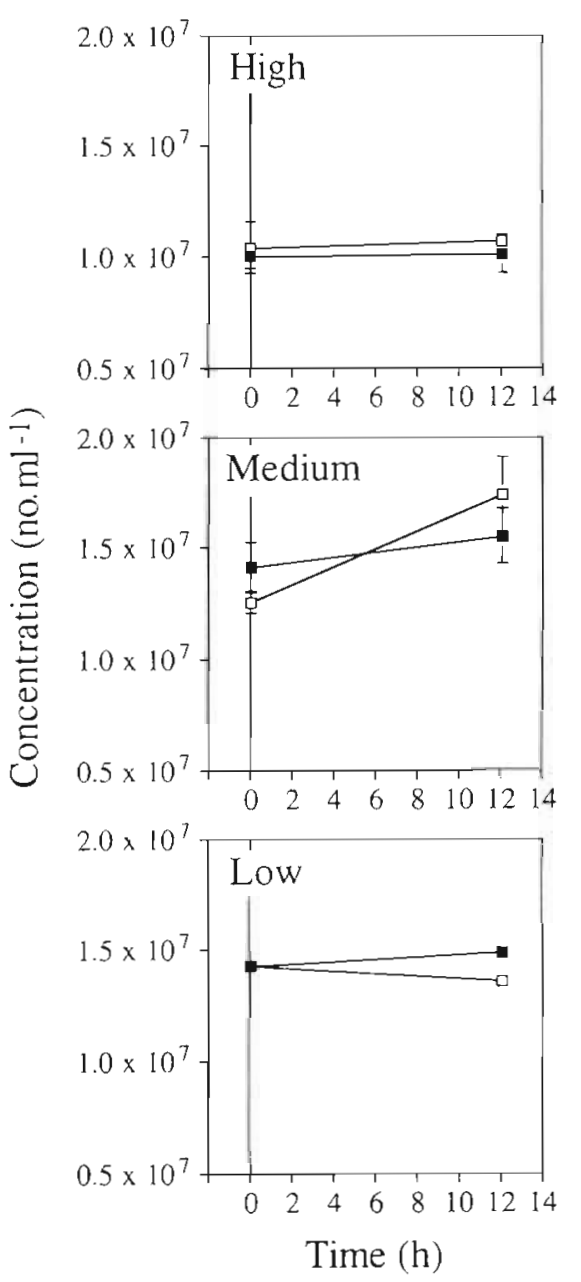

Fig. 5. Change over time of bacterial concentrations in the low, medium and high turbulence level experiments. Symbols are means of 3 replicates and bars correspond to $\pm 1 \mathrm{SE}$. ( turbulence treatment; (ㅁ) non-turbulence control to a p-value of 0.24 for the percentage change based on per cell ingestion rate. On the average normalized values increased $87 \%$ for the turbulence treatment and only $2.0 \%$ for the non-turbulence control, but the variability among replicates masked the possible differences.

An additional control experiment was done at the high turbulence level in which no flagellates were added to the experimental system. The purpose was to discern whether turbulence had an influence on bacterial growth in the absence of predation. Bacterial concentrations remained unchanged ( $p=0.162$ ) after $24 \mathrm{~h}$, and there were no differences between treatments in bacterial concentrations ( $p=0.692)$. At $24 \mathrm{~h}$, the experimental vessels were sampled again after vigorous stirring to see whether bacteria were homogeneously distributed. There was no statistical difference in the concentration of bacteria before and after stirring. The
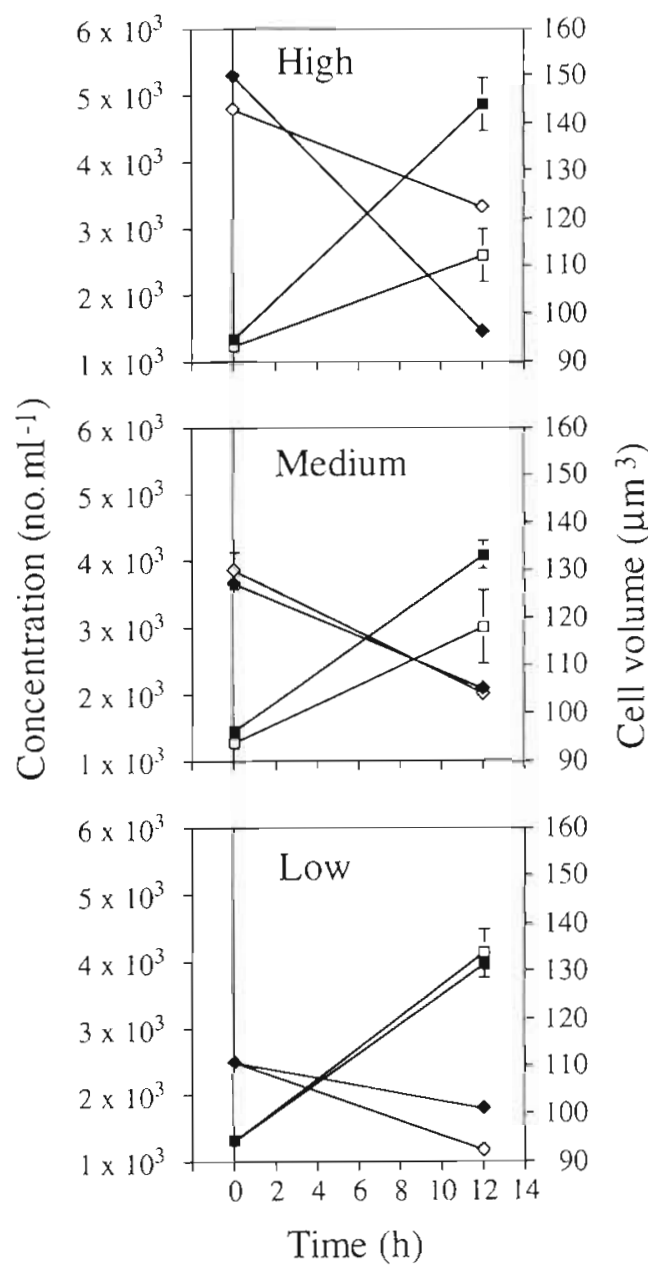

Fig. 6. Change over time of flagellate concentration (squares) and flagellate cell volume (diamonds) in the different turbulence experiments. Filled symbols: turbulence treatment; open symbols: non-turbulence control. Remaining notation as in Fig. 5 
Table 2. Summary of statistical results for different biological parameters in response to turbulence (turb) and incubation time (time) at different turbulence intensities. Tests conducted were 2-way ANOVA and Student's $t$-test between \% change (Eq. 2). ns: $0.05<\alpha_{i} \cdot 0.01<\alpha \leq 0.05$ $\cdots \alpha \leq 0.01$. Signs indicate whether significant changes are increases (+) or decreases (-) over the non-turbulence controls

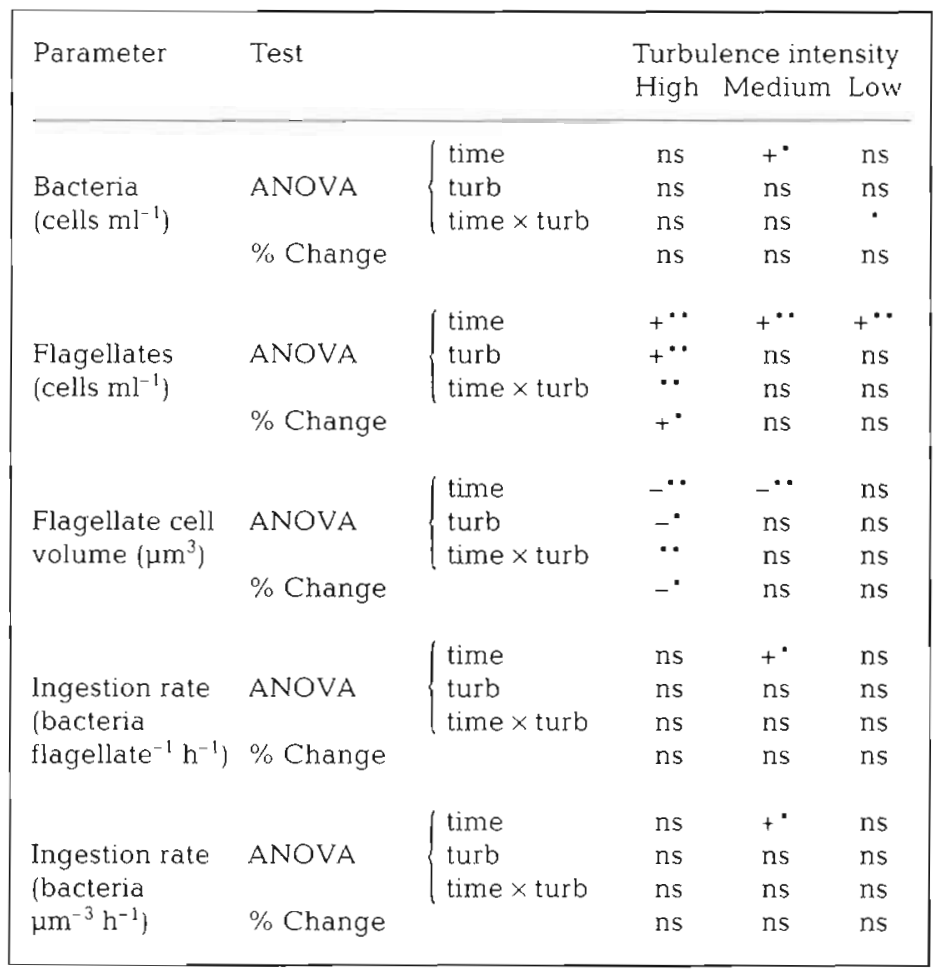

same results were observed in the case of FLB. Although the concentration of FLB appears slightly lower after $24 \mathrm{~h}$, the difference is not statistically significant ( $p=0.135$ ). This trend was observed for both treatments. Based on these results, it is assumed that any small differences in food concentration, if real, would be much smaller after only $12 \mathrm{~h}$. Hence, any significant differences in bacterial concentrations, when flagellates are present, are likely to result from grazing (if bacteria decrease) or from growth enhancement owing to nutrients regenerated by the flagellates (if bacteria increase).

\section{DISCUSSION}

\section{Comparison between theoretical and measured $\varepsilon$}

Theoretically calculated and empirically measured energy dissipation rates agreed quite well in the high range of oscillation rates (Table 1). However, at the lowest oscillation rate - $1.23 \mathrm{rpm}$ - there is a major discrepancy, and theoretical values are much lower. The theoretical values are obtained from estimates of the energy put into the system at the different oscillation rates and are based on hydrodynamic considerations of the grid. So, this value gives an estimate of an average dissipation rate for the system. On the other hand, measured average $\varepsilon$ are point estimates in space. The values presented in Table 1 are for the center of the beaker. Although average dissipation rate is statistically isotropic in the vertical direction, there was an observed trend to slightly smaller values away from the grid center and a composite average dissipation rate for the whole beaker would be somewhat smaller. But this would be true for all oscillation rates and not only the slowest ones.

Average $\varepsilon$ was not measured directly at the 2 lowest rpm settings (see 'Results'). Their

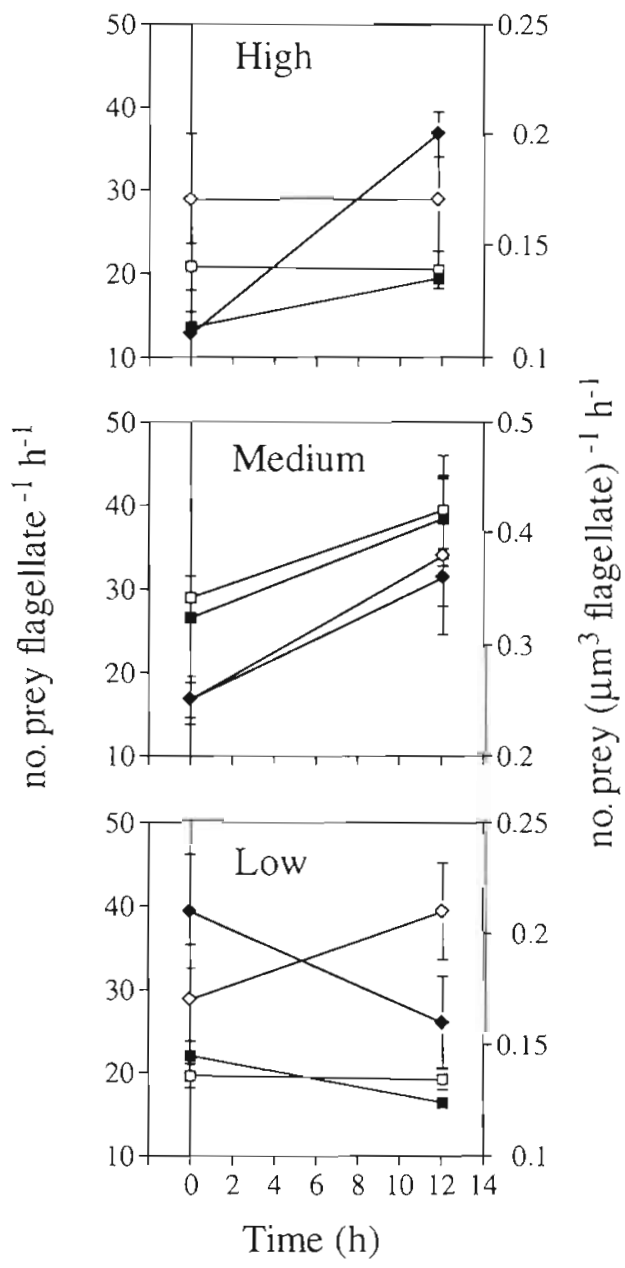

Fig. 7. Change over time of ingestion rate (squares) and volume normalized ingestion rate (diamonds) in the different turbulence experiments. Notation as in Fig. 6 
estimates were extrapolated from the relationship between $q$ and $\varepsilon$ at higher oscillation rates. Perhaps this relationship does not hold at low oscillation rates as well as it does at higher oscillations. Some points seem to depart from the regression line at $1.23 \mathrm{rpm}$ (Fig. 4) and could represent the start of a break in the relationship. We do not have enough data points in that region to confirm or discard this hypothesis. Theoretically this break could be caused by an increasing importance of viscous shear. If so, points with average $q$ below $0.15 \mathrm{~cm}^{2} \mathrm{~s}^{-2}$ would correspond to dissipation rate values lower than the ones now predicted and more in accord with the theoretical estimates. On the other hand, theoretical estimates could be slightly biased because calculations were made assuming a constant drag coefficient for the grid, when in reality drag coefficients increase with decreasing Reynolds number $(R e)$. Lower oscillation rates result in lower $R e$ and consequently higher $\varepsilon$. In any case, the measured values of average $\varepsilon$ are maximum possible values, while average $\varepsilon$ at low oscillation rates probably lie within the theoretical estimates and the predicted values from the regression.

\section{Feeding, size and gross growth efficiency}

Bacterial concentrations, as expected from our preliminary calculations, remained fairly constant for the $12 \mathrm{~h}$ incubation period. This was necessary to ensure homogeneous conditions at time 0 and $12 \mathrm{~h}$. For the low and high turbulence experiments, ingestion rates were also constant throughout the incubation. Therefore, with the data on concentration and flagellate cell volume, assuming no flagellate mortality, we can calculate the total flagellate biovolume produced $(F P)$ as:

$$
F P\left(\mu \mathrm{m}^{3} \mathrm{ml}^{-1} \mathrm{~d}^{-1}\right)=\left(F V_{\mathrm{i}} \times F C_{1}-F V_{1} \times F C_{1}\right) /\left(t_{\mathrm{f}}-t_{1}\right)
$$

where $F V$ is flagellate cell volume, FC is flagellate concentration, $t$ is time, and the subscripts denote final ( $f$ ) and initial (i) and refer to the experiment endpoints.

We can also calculate how much bacterial biovolume was consumed by the flagellates $(B C)$, using the information of the per cell ingestion rate and its constancy over time:

$$
B C\left(\mu \mathrm{m}^{3} \mathrm{ml}^{-1} \mathrm{~d}^{-1}\right)=I R \times B V \times A V E F C
$$

where $I R$ is ingestion rate, $B V$ is bacterial cell volume and $A V E F C$ is an average flagellate concentration. $A V E F C$ was calculated assuming an exponential increase over time in flagellate concentration, and applying the equations developed by Frost (1.972) and Heinbokel (1978). IR was calculated as an arithmetic average between the estimates of the endpoints. This would not be strictly correct in the case of the medium level turbulence experiment, where ingestion rate is statistically different between the endpoints and we have no way to know its dynamic nature during the incubation period. However, all other parameters in this experiment follow identical trends as in the other two, thus the estimation of $I R$ appears reasonable. We assume, therefore, that we are introducing a minor error by using a mean $I R$ in this case.

Gross growth efficiency ( $G G E$ ) values, calculated as $F P / B C$, are shown in Fig. $8 \mathrm{~A}$. We do not deem it appropriate to compare absolute values of $G G E$ between experiments because each turbulence level experiment was done using a different batch of protozoa and bacteria. We put effort into using protozoa and bacteria that were in the same physiological state, and in making starting concentrations uniform, but it is impossible to achieve complete uniformity between experiments. The absolute values of efficiencies are similar to values reported in the literature (Caron \& Goldman 1990) which have a range of 12 to $45 \%$ and a mean of $31 \%$. Ratios of growth efficiencies, calculated between the turbulence and the non-turbulence treatment, can be compared across experiments (Fig. 8B).
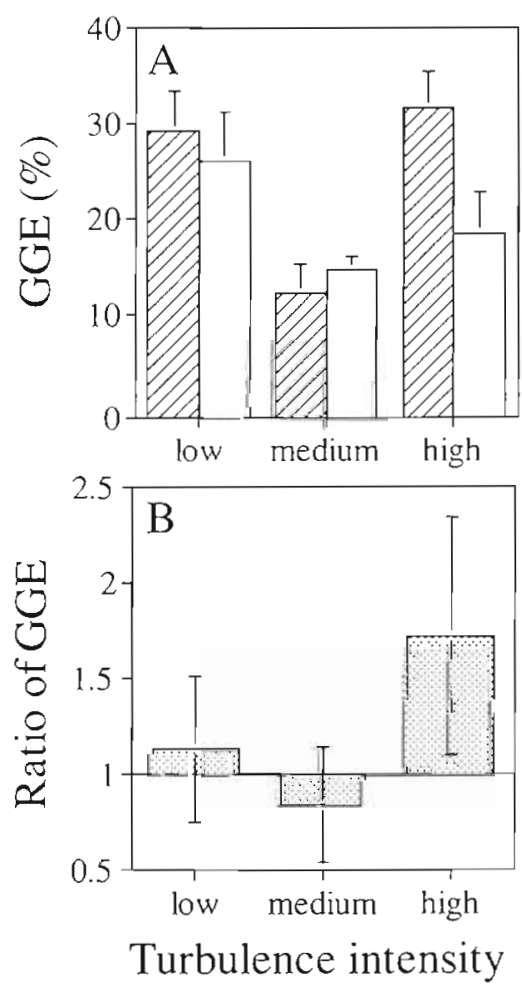

Fig 8. (A) Gross growth efficiency (GGE) for the turbulence (hatched bars) and non-turbulence (open bars) treatments for the different turbulence experiments; and $(B)$ the ratio of the efficiency in the turbulence over the efficiency in the nonturbulence treatment. Error bars are $\pm 1 \mathrm{SE}$ in (A) and were calculated by error propagation theory in (B) 
The ratios presented values of $1.1,0.8$ and 1.7 for the low, medium and high turbulence experiments respectively, but none of them was statistically different from 1 .

Flagellate size decreased over time in all experiments and treatments and is most likely a consequence of the adaptation to lower prey concentration with respect to the stock culture (ca $1 \times 10^{9}$ bacteria $\mathrm{ml}^{-1}$ ). It is known that microflagellates, when entering an environment of low food concentration, such as the stationary phase of a batch culture, undergo 1 or 2 cell divisions with little increase in biomass (Fenchel 1982b). This is hypothesized to be an adaptation to starvation conditions. Cells reduce their metabolic activity but maintain their ability to resume growth rapidly once food becomes available.

In this study, food concentrations $\left(10^{7}\right.$ bact $\left.\mathrm{ml}^{-1}\right)$ can be considered only mild starvation conditions and changes in protozoan size were not nearly as drastic. While flagellates underwent about 1 cell division over the incubation period, the decrease in diameter was only $7 \%$ on the average. A decrease of ca $21 \%$ in cell diameter would be expected for one division under starvation conditions. Ingestion rate did not decrease accordingly with cell size. Paraphysomonas imperforata is a raptorial feeder (Fenchel 1982a). The encounter rate for such an organism and suspended food particles is dominated by direct interception:

$$
\mathrm{E}_{R}=\frac{3}{2} \pi U r_{p}^{2} C
$$

where $\mathrm{E}_{R}$ is the encounter rate, $U$ is a composite velocity of water moving past the predator and, in still water, is the swimming speed of the flagellate, $r_{p}$ is the prey particle radius, and $C$ is particle concentration. This equation applies when $r_{p}$ is much smaller than the radius of the predator. Direct interception in our experiments is about 7 times more important than encounter owing to diffusion of prey particles (estimated with Eq. 3 of Shimeta 1993), which does depend on (predator radius $)^{4 / 3}$. Thus, $P$. imperforata does not much decrease its encounter rate by somewhat decreasing its size. As particle concentration decreases, so does $E_{R}$. A reduction in size will then help flagellates maintain an energetic competitive advantage, as metabolic costs are reduced while encounter rate is maintained.

Overall, it appears that turbulence does not affect the physiology, feeding, or growth efficiency of Paraphysomonas imperforata, except at the highest turbulence level. The variability among replicates was quite high in some cases despite our efforts to prevent it. Perhaps a larger number of replicates would have statistically reduced the error and/or helped to eliminate possible outliers, giving more resolution between treatments. As it is now, it is impossible to tell whether one replicate that differs from the other two is a true outlier or not, and we did not eliminate any data points that possibly could have reduced the variability.

High turbulence affected flagellate size and most likely also per volume ingestion rate and growth efficiency. These differences came mainly from a greater reduction in flagellate size and a higher growth rate under turbulence with respect to the non-turbulence treatment. Higher growth rates while flagellates, even if smaller, maintain their ingestion rates, imply that the total consumption of bacteria must be higher under high turbulence. In fact, 20\% more bacterial biovolume was consumed under high turbulence in the $12 \mathrm{~h}$ period, although the impact on the prey population cannot be seen reflected in changes in bacterial concentrations at the conditions and incubation time used in these experiments. The positive implications that a higher growth rate, higher total grazing and possibly higher efficiency have for a predator population discard the possibility that protozoa are 'stressed' under high turbulence and that the decrease in size is a consequence of it.

At the high turbulence level, hydrodynamic motion probably helped maintain high encounter rates by affecting $U$, and the energy saved by swimming and searching increased the growth efficiency. Swimming has been usually assumed to represent a small fraction of the energy budget of protozoa during non-limiting food concentrations (Fenchel 1987). Thus, it would be unlikely that processes that increase encounter would affect the energy budget of a protozoan. However, when encounter rate becomes limiting, costs of motility can increase more than 100-fold (Fenchel 1987, Crawford 1992). In light of the reduction in protozoan cell size, the food concentration used in this study started to limit encounter rate. Hence, high turbulence could have affected the energetics of Paraphysomonas imperforata by increasing encounter owing to water motion as compared to swimming.

High turbulence could have also affected other aspects related to feeding that are more behavioral in nature. Flagellates have been shown to have chemosensory responses to selected chemicals (see Bennett et al. 1988 and references therein). How these organisms sense the environment they are in and how they respond biochemically to its fluctuations is a crucial aspect to understanding their behavior and physiology and, as a consequence, their ecology. Unfortunately, little is known about these aspects. Perhaps, the concentration and/or distribution of chemicals that give cues for prey presence and concentration to the flagellates is altered by high turbulence. Flagellates under such conditions could be more efficient at responding to the cues and/or finding the source that originated them. 


\section{Comparison to other taxa and importance of turbulence}

We can compare the present study with previous investigations of calanoid copepods (Marrasé et al. 1990, Saiz \& Alcaraz 1991, Saiz \& Alcaraz 1992a, Saiz et al. 1992). In those studies, higher ingestion rates under turbulence (microscale ranging from 500 to $650 \mu \mathrm{m}$ ) were explained by higher encounter rates with prey particles. In the case of flagellates, even at the high turbulence level, the Kolmogorov microscale $(150 \mu \mathrm{m})$ is over an order of magnitude larger than the size of the organisms, and increases in encounter produced by uncorrelated velocity fluctuations are unlikely. Perhaps other mechanisms, such a linear shear field (Shimeta 1993), can increase encounter rates at these scales. However, evidence has now accumulated (Peters \& Gross 1994, Shimeta et al. 1995, Peters \& Choi unpubl., this study) for Paraphysomonas imperforata that any possible increases in encounter under turbulence are not translated into higher per cell ingestion rates.

Copepods change their size, physiology and behavior under turbulence (Costello et al. 1990, Saiz \& Alcaraz 1992a, b, Saiz et al. 1992). Faster development times and smaller sizes under turbulence parallel the responses obtained with Paraphysomonas imperforata, although the mechanisms of action may not be similar between these 2 groups of organisms. On the contrary, copepods under turbulence have a higher energy expenditure caused by increased escape reactions, while the growth efficiency of $P$. imperforata was not statistically affected by turbulence and, if anything, it showed a trend to increase

It remains to be seen how important and frequent are turbulence events with energy dissipation rates on the order of $10 \mathrm{~cm}^{2} \mathrm{~s}^{-3}$ in the ocean. Buoy and satellite measurements (Cardone et al. 1983, Pierson 1983) show that wind speeds of $40 \mathrm{~m} \mathrm{~s}^{-1}$ are achieved during storms, bursts of $25 \mathrm{~m} \mathrm{~s}^{-1}$ are common, and that average wind speeds of $15 \mathrm{~m} \mathrm{~s}^{-1}$ are maintained for around $12 \mathrm{~h}$. At this wind speed and at $1 \mathrm{~m}$ depth, energy dissipation rates would be around $0.2 \mathrm{~cm}^{2} \mathrm{~s}^{-3}$ (MacKenzie \& Leggett 1993; Eq. 6), a value similar to our medium intensity setting. Where logistics have actually permitted direct measurements of $\varepsilon$ near the surface under stormy conditions, values in the range of 100 to 1000 $\mathrm{cm}^{2} \mathrm{~s}^{-3}$ have been reported (George et al. 1994). Furthermore, energy dissipation rate measurements could be underestimated by 3 orders of magnitude in the upper $10 \mathrm{~m}$ under intermittent stormy weather by interactions of surface and internal waves with the stratified density profile and fossil turbulence density microstructure (Gargett 1989, Thomas \& Gibson 1990). Thus, protozoa living in the surface ocean are likely to experience turbulence levels similar or even higher than in our high turbulence setting.

Grazing rates on bacteria after $12 \mathrm{~h}$ incubations were 5 -fold (range of 0.9 - to 18-fold) higher under high turbulence in the Gulf of Mexico (Peters \& Gross 1994). Assuming a bacterial growth rate of $1 \mathrm{~d}^{-1}$ and a grazing rate on bacteria of $0.5 \mathrm{~d}^{-1}$ under still conditions, high turbulence can increase grazing rates enough to exert a control on the bacterial population. If Paraphysomonas imperforata is a good representative of the natural protozoan community, increases in grazing on bacteria under turbulence will not occur through higher ingestion rates but through some indirect effects on the physiology of protozoa. On the other hand, a few experiments with filter-feeding protozoa have shown an effect of turbulence on ingestion rates (Shimeta et al. 1995). More studies are needed on this subject, especially to find out if there is a generality in the responses of protozoa to turbulence, so that experiments and interpretations can be made at the community and system levels. If turbulence can enhance the grazing process (in some way or another) and, moreover, higher efficiencies are achieved, it can have important effects not only on population dynamics and control but also on carbon transfer and nutrient cycling.

The present study helps explain some of the observed effects of high turbulence on the dynamics of growth and grazing of a particular protozoan. Extrapolations of these results to natural systems, with a plethora of taxa and feeding mechanisms, remains speculative at this point. Two general points can be emphasized. The first is that turbulence can increase grazing rates of protozoa on bacteria below the Kolmogorov length scale, where viscous forces are thought to dominate motion and eddies no longer exist. This is in tune with recent theoretical and empirical studies on the same issue (Shimeta 1993, Peters \& Gross 1994, Shimeta et al. 1995). The importance of this finding for both biology and physics is independent of the detailed mechanism of action and the relevance of laboratory turbulence settings with respect to natural conditions. Second, there is a need for long-term incubations (hours to days) when assessing the influence of turbulence, since protozoa can show physiological changes that are not instantaneous responses.

Acknowledgements. We thank Larry Pomeroy, Judy Meyer, Mary Ann Moran, Enric Saiz, Peter Verity, Bill Wiebe and 2 anonymous reviewers for critical comments on the manuscript. This work was supported by NSF grant OPP 9223007 to L. R. Pomeroy and W. J. Wiebe.

\section{LITERATURE CITED}

Bennett SJ, Sanders RW, Porter KG (1988) Chemosensory responses of heterotrophic and mixotrophic flagellates to potential food sources. Bull Mar Sci 43:764-771 
Berdalet $E$ (1992) Effects of turbulence on the marine dinoflagellate Gymnodinium nelsonii. J Phycol 28:267-272

Cardone V, Chester T, Lipes R (1983) Evaluation of SEASAT SMMR wind speed measurements. J Geophys Res 88: $1709-1726$

Caron DA, Goldman JC (1990) Protozoan nutrient regeneration. In: Capriulo GM (ed) Ecology of marine protozoa. Oxford University Press, New York, p 283-306

Choi JW (1994) The dynamic nature of protistan ingestion response to prey abundance. J Euk Microbiol $41 \quad 137-146$

Choi JW, Peters F (1992) Elfects of temperature on two psychrophilic ecotypes of a heterotrophic nanoflagellate, Paraphysomonas imperforata. Appl Environ Microbrol 58: $593-599$

Costello JH, Strickler JR, Marrasé C, Trager G, Zeller R, Freise AJ (1990) Grazing in a turbulent environment: behavioral response of a calanoid copepod, Centropages hamatus. Proc Natl Acad Sci USA 87:1648-1652

Crawford DW (1992) Metabolic cost of motility in planktonic protists: theoretical considerations on size scaling and swimming speed. Microb Ecol 24:1-10

Fenchel T (1982a) Ecology of heterotrophic microflagellates I. Some important forms and their functional morphology. Mar Ecol Prog Ser 8:211-223

Fenchel T (1982b) Ecology of heterotrophic microflagellates. III. Adaptations to heterogeneous environments. Mar Ecol Prog Ser 9:25-33

Fenchel T (1987) Ecology of protozoa. Springer-Verlag, New York

Frost BW (1972) Effects of size and concentration of food particles on the feeding behavior of the marine planktonic copepod Calanus pacificus. Limnol Oceanogr 17. $805-815$

Gargett A (1989) Ocean turbulence. Ann Rev Fluid Mech 21. $419-451$

George R, Flick RE, Guza RT (1994) Observations of turbulence in the surf zone. J Geophys Res 99: 801-810

Haury LR, Yamazaki H, Itsweire EC (1990) Effects turbulent shear flow on zooplankton distribution. Deep Sea Res 37 . $447-461$

Heinbokel JF (1978) Studies on the functional role of tintinnids in the Southern Califormia Bight. I. Grazing and growth rates in laboratory cultures. Mar Biol 47:177-189

Hellung-Larsen P, Lyhne I (1992) Effect of shaking on the growth of diluted cultures of Tetrahymena. J Protozool 39: $345-349$

Mackenzie BR, Leggett WC (1991) Quantifying the contribution of small-scale turbulence to the encounter rates between larval fish and their zooplankton prey: effects of wind and tide. Mar Ecol Prog Ser 73:149-160

Mackenzie BR, Leggett WC (1993) Wind-based models for estimating the dissipation rates of turbulent energy in aquatic environments: empirical comparisons. Mar Ecol Prog Ser 94:207-216

Marrasé C, Costello JH, Granata T, Strickler JR (1990) Grazing in a turbulent environment: energy dissipation, en-

This article was submitted to the editor counter rates, and efficacy of feeding currents in Centropages hamatus. Proc Natl Acad Sci USA 87:1653-1657

Peters F, Gross T (1994) Increased grazing rates of microplankton in response to small-scale turbulence. Mar Ecol Prog Ser 115:299-307

Pierson WJ Jr (1983) The measurement of the synoptic scale wind over the ocean. J Geophys Res 88:1683-1708

Pollingher U, Zemel E (1981) In situ and experimental evjdence of the influence of turbulence on cell division processes of Peridinium cinctum forma westii (Lemm) Lefèvre. Br Phycol J 16:281-287

Rothschild BJ, Osborn TR (1988) Small-scale turbulence and plankton contact rates. J Plankton Res 10:465-474

Saiz E, Alcaraz M (1991) Effects of small-scale turbulence on development time and growth of Acartia grani (Copepoda: Calanoida). J Plankton Res 13:873-883

Saiz E, Alcaraz M (1992a) Enhanced excretion rates induced by small-scale turbulence in Acartia (Copepoda: Calanoida). J Plankton Res 14:681-689

Saiz E, Alcaraz M (1992b) Free-swimming behaviour of Acartia clausi (Copepoda: Calanoida) under turbulent water movement. Mar Ecol Prog Ser 80:229-236

Saiz E, Alcaraz M, Paffenhöfer GA (1992) Effects of smallscale turbulence on feeding rate and gross-growth efficiency of three Acartia species (Copepoda: Calanoida). J Plankton Res 14:1085-1097

Sherr BF, Sherr EB, Fallon RD (1987) Use of monodispersed, fluorescently labeled bacteria to estimate in situ protozoan bacterivory. Appl Environ Microbiol 53:958-965

Shimeta J (1993) Diffusional encounter of submicrometer particles and small cells by suspension feeders. Limnol Oceanogr 38:456-465

Shimeta J, Jumars PA, Lessard EJ (1995) Influences of turbulence on suspension feeding by planktonic protozoa; experiments in laminar shear fields. Limnol Oceanogr 40: 845-859

Sundby S, Fossum P (1990) Feeding conditions of Arcto-Norwegian cod larvae compared with the Rothschild-Osborn theory on small-scale turbulence and plankton contact rates. J Plankton Res 12:1153-1162

Tennekes H, Lumley JL (1972) A first course in turbulence. MIT, Cambridge, MA

Thomas WH, Gibson CH (1990) Quantified small-scale turbulence inhibits a red tide dinoflagellate, Gonyaulax polyedra Stein. Deep Sea Res 37:1583-1593

Thomas WH, Gibson CH (1992) Effects of quantified smallscale turbulence on the dinoflagellate Gymnodinum sanguineum (splendens): contrast with Gonyaulax (Lingulodiniuml polyedra, and the fishery implication. Deep Sea Res 39:1429-1437

White AW (1976) Growth inhibition caused by turbulence in the toxic marine dinoflagellate Gonyaulax excavata. J Fish Res Bd Can 33:2598-2602

Yamazaki H, Osborn TR, Squires KD (1991) Direct numerical simulation of planktonic contact in turbulent flow. J Plankton Res 13:629-643

Manuscript first received: February 2, 1995

Revised version accepted: October 23, 1995 